\title{
Special Issue Fire and the Atmosphere
}

\author{
Scott L. Goodrick
}

check for updates

Citation: Goodrick, S.L. Special Issue Fire and the Atmosphere. Atmosphere 2021, 12, 66. https://doi.org/ 10.3390/atmos12010066

Received: 3 December 2020 Accepted: 30 December 2020 Published: 5 January 2021

Publisher's Note: MDPI stays neutral with regard to jurisdictional clai$\mathrm{ms}$ in published maps and institutional affiliations.

Copyright: $\odot 2021$ by the author. Licensee MDPI, Basel, Switzerland. This article is an open access article distributed under the terms and conditions of the Creative Commons Attribution (CC BY) license (https:// creativecommons.org/licenses/by/ $4.0 /)$.
USDA Forest Service, Southern Research Station, Athens, GA 30602, USA; scott.l.goodrick@usda.gov

This Atmosphere Special Issue on "Fire and the Atmosphere" explores the atmosphere's role in a range of wildland fire related topics through 14 papers covering fire spread, fuels, climate change, fire behavior, smoke, fire weather and fire climate relationships. The papers can be loosely grouped into four categories: fire weather and climate, numerical modeling, smoke impacts and designing field measurement campaigns.

A key aspect of fire weather is being able to identify when weather conditions will make a wildland fires difficult to manage. Three of the four papers in the fire weather and climate category focus on fire weather indices, common tools for combining weather variables to reduce complex processes down to a more easily understood scale. Potter conducts a quantitative evaluation of the relationship between major fire growth events and the Haines Index, an index designed to link mid-tropospheric conditions to large or erratic wildfires. Srock et al. describe a new fire weather index, the Hot-Dry-Windy (HDW) index. The new index is based on the meteorological variables which govern the potential for the atmosphere to affect a fire both at the Earth's surface and in a $500 \mathrm{~m}$ layer just above the surface. The results indicate that HDW can identify days where weather processes can contribute to dangerous fire behavior. McDonald et al. further develop the utility of the HDW through the development of a 30 year HDW climatology for the contiguous United States to provide index values with historical contexts. In the final paper of the group, Clabo employs a climatological analysis to explore the relative roles of regional climate and land use on the spatiotemporal wildfire distribution across the state of South Dakota (SD), USA.

The three papers in the numerical modeling category focus on the application of coupled fire-atmosphere models to case studies describing the spread of specific wildfires. Coen et al. investigate the role of a strong Diablo wind event underlying the extreme fire behavior on the Tubbs Fire in northern California, USA. With a $370 \mathrm{~m}$ horizontal grid spacing, the numerical weather model adequately captured the wind variability to simulate an on-time fire arrival in Santa Rosa, CA, with calculations executed faster than real-time on a single computer processor. Similarly, Jimenez et al. use a different fire forecast system based on a numerical weather prediction model coupled with a wildland fire behavior model to simulate conditions for the Chimney Tops II wildland fire responsible for large socio-economic impacts in the region around Gatlinburg, TN, USA in 2016. Filippi et al. use a different coupled fire-atmosphere modeling system to examine the Aullene fire on the island of Corsica in July 2009, focusing on the strong fire-atmosphere interactions that drove intense convective updrafts and strong inflow into the base of the convective updrafts. An encouraging thread linking these papers is the availability of computational power to make such simulations possible not only for research, but also as a potential forecasting tool.

The five papers in the smoke category cover a diverse range of topics. Hsieh et al. apply multi-element scanning thermal analysis (MESTA) to the thermochemical properties of PM2.5 emissions from prescribed fires, which may prove useful in discerning differential diffusion between PM2.5 and gases and provide insight into the impact of PM emission on atmospheric environment and public health. Arunrat et al. focus on differences in emissions from agricultural land as determined by land use patterns in Mae Chaem basin, Chiang Mai Province, Thailand. Particulate pollution is a common concern associated 
with the burning of crop residues in highland agricultural systems. Mallia et al. employ an atmospheric modeling framework with various plume rise parameterizations to the RxCADRE field experiment to assess the impact of different plume parameterizations on downwind smoke distributions. Odman et al. shift to a more regional perspective with their evaluation of a modeling system for predicting prescribed fire air quality impacts. The forecasting system is intended to facilitate more dynamic management of air quality by modulating prescribed burn activity through a new decision tree model that predicts burn activity based on the weather forecast and historic burning patterns. In the final paper in the smoke group, Navarro et al. provide a review comparing the differences in community smoke exposure from wildfires and prescribed fires. The lack of consistency in how air quality was assessed by the studies included in the review highlights a need for research specifically targeted at assessing potential differences in air quality impacts from different wildland fire types.

The remaining two papers explore how future field campaigns could be designed to best advance our understanding of coupled fire-atmosphere processes. Kochanski et al. integrate historical meteorological data for a proposed experiment site with a coupled fire-atmosphere modeling system and advanced sensitivity analysis to design optimal measurement plans. Using a number of smoke modeling tools, Liu et al. identify synoptic weather patterns likely to produce desired smoke plume traits for the Fire and Smoke Model Evaluation Experiment (FASMEE). These two studies illustrate the value of close collaboration between measurement groups and modelers to design measurement campaigns of maximal value.

The goal of this Special Issue is to extend fire and forest meteorology science, as well as offer applied concepts for fire management practitioners. The 14 papers in this Special Issue realize this goal through the description of a new fire weather index, the demonstration of the capabilities of today's coupled fire-atmosphere modeling systems and their potential to operate as a forecast tool, and the application of modeling tools to the optimization of field measurement campaigns. A critical avenue of research identified in this issue is developing better means of comparing community smoke exposure from wildfires and prescribed fires, because prescribed fire is widely considered a critical tool for managing many ecosystems, particularly those choked with excessive fuel accumulations due to previous fire exclusion.

Funding: This research received no external funding.

Acknowledgments: The editor would like to thank the authors for their contributions, the reviewers for their comments and the editorial office for the support in publishing this special issue.

Conflicts of Interest: The author declares no conflict of interest. 